\title{
Úlceras vulvares agudas en adolescentes, reporte de una serie de casos clínicos
}

\author{
Lucía Moreira*, Loreley Garcíał, Ana Casuriagał, Gustavo Giachetto§, Víctor Machín"
}

\section{Resumen}

Introducción: las úlceras genitales se caracterizan por su gran heterogeneidad clínica y etiológica. Pueden corresponder a entidades patológicas cutáneas o sistémicas de naturaleza infecciosa o no infecciosa. Dentro de estas últimas, se destacan las úlceras de Lipschütz y la enfermedad de Behcet.

Objetivo: describir cuatro casos clínicos de adolescentes con úlceras vulvares agudas de causa no infecciosa hospitalizadas en dos prestadores del Sistema Nacional Integrado de Salud de Montevideo con el objetivo de brindar herramientas a profesionales para el correcto abordaje diagnóstico y terapéutico.

Discusión: la realización de una anamnesis detallada y un examen físico minucioso son esenciales para realizar un adecuado abordaje diagnóstico y terapéutico. En el análisis clínico es importante considerar la edad de la paciente, el inicio de relaciones sexuales, el número, topografía y características de las úlceras incluyendo la presencia o no de dolor, así como la asociación de manifestaciones sistémicas. Resulta necesario el conocimiento de esta patología poco frecuente en niñas y adolescentes cuyo abordaje diagnóstico y terapéutico depende de la orientación etiológica basada en criterios epidemiológicos y clínicos bien definidos. Ello contribuirá a mejorar la calidad de la asistencia y a minimizar las repercusiones biológicas y psicológicas.

Palabras clave: Úlcera genital aguda

Úlcera de Lipschütz

Enfermedades de la vulva

Key words: $\quad$ Acute genital ulcer

Lipschütz ulcer

Vulvar diseases

\footnotetext{
* Residente de Pediatría, Asociación Española.

† Profesora Agregada de Clínica Pediátrica. Departamento de Pediatría y Especialidades. Facultad de Medicina. Universidad de la República.

$\ddagger$ Asistente de Clínica Pediátrica. Departamento de Pediatría y Especialidades. Facultad de Medicina. Universidad de la República.

$\S$ Profesor de Clínica Pediátrica. Departamento de Pediatría y Especialidades. Facultad de Medicina. Universidad de la República.

II Profesor Adjunto de Ginecología. Facultad de Medicina. Universidad de la República.

Correspondencia: Dra. Ana Laura Casuriaga. Bulevar Artigas 1471. Montevideo, Uruguay. Correo electrónico: anitacasuriaga7@gmail.com

Los autores declaran no tener conflicto de interés.

Se cuenta con el consentimiento de todas las pacientes para la publicación.

Recibido: $26 / 5 / 19$

Aprobado: 9/9/19
} 


\section{Introducción}

La patología ginecológica en la infancia y adolescencia representa un desafío diagnóstico ${ }^{(1)}$.

Las úlceras genitales se caracterizan por su gran heterogeneidad clínica y etiológica. Pueden ser un signo guía de un gran abanico de entidades patológicas cutáneas o sistémicas de naturaleza infecciosa o no infeccio$\mathrm{sa}^{(2)}$. Por otro lado, suelen generar importante repercusión psicológica y gran ansiedad familiar ${ }^{(3)}$.

Entre las causas infecciosas el agente etiológico más frecuente es el virus herpes simple (VHS) seguido de Treponema pallidum, Haemophilus ducreyi y virus de inmunodeficiencia humana (VIH).

Entre las causas no infecciosas, las úlceras vulvares pueden estar vinculadas a patología traumática, autoinmune, tóxica y neoplásica. En este grupo se destacan las úlceras de Lipschütz y la enfermedad de Behcet.

La realización de una anamnesis detallada y un examen físico minucioso son esenciales para realizar un adecuado abordaje diagnóstico y terapéutico ${ }^{(2)}$. En el análisis clínico es importante considerar la edad de la paciente, el inicio de relaciones sexuales, el número, topografía y características de las úlceras incluyendo la presencia o no de dolor, así como la asociación de manifestaciones sistémicas.

Hasta la fecha, en nuestro medio, no se dispone de comunicaciones acerca de la frecuencia y características de esta patología.

A continuación se presenta una serie de cuatro casos clínicos de adolescentes que consultaron por úlceras vulvares agudas, sin inicio de relaciones sexuales ni evidencia de abuso sexual, que fueron asistidas en dos prestadores del Sistema Nacional Integrado de Salud de Montevideo, uno público y otro privado. En esta comunicación se describe la forma de presentación clínica de dos de las etiologías más importantes de úlceras vulvares de causa no infecciosa. El objetivo es brindar herramientas para el correcto abordaje diagnóstico y terapéutico.

\section{Casos clínicos}

\section{Caso 1}

Catorce años, antecedentes personales (AP): úlceras bucales recurrentes desde la primera infancia, sacroileítis en noviembre de 2018. Menarca a los 11 años, ciclos regulares. Niega inicio de relaciones sexuales (IRS).

Consulta en servicio de emergencia (SE) en enero de 2019 por lesiones vulvares dolorosas de cuatro días de evolución, fiebre de hasta $39^{\circ} \mathrm{C}$ axilar y dolor abdominal difuso. No traumatismos, ni ingesta de fármacos. $\mathrm{Al}$ examen físico genital: edema de labios menores, cuatro lesiones vulvares ulcerosas de fondo purulento y necrótico, una

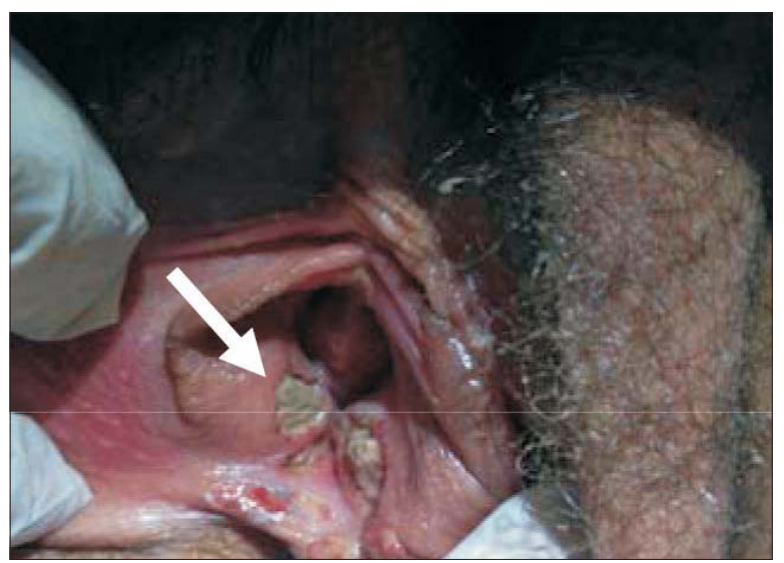

Figura 1. Se observan úlceras vulvares en espejo.

en horquilla vulvar en espejo con las mismas características, muy dolorosas (figura 1). Resto del examen normal. Se realiza exudado de lesiones y se indica tratamiento ambulatorio con metronidazol, claritromicina y prednisona 20 $\mathrm{mg}$ vía oral/día. En la evolución agrega dolor intenso y retención aguda de orina, por lo que ingresa a sector de cuidados moderados. Los principales estudios complementarios realizados se exponen en la tabla 1 . Se aumentó dosis de prednisona a $40 \mathrm{mg} /$ día y se indicó analgesia local y sistémica con excelente evolución, por lo que se otorgó alta a las 48 horas. A la semana del egreso, en interconsulta con especialista en enfermedades autoinmunes, se plantea enfermedad de Behcet y se inicia azatioprina.

\section{Caso 2}

Once años, sin AP a destacar. No menarca, ni IRS.

Consulta por lesiones genitales dolorosas de aparición súbita, fiebre de $38^{\circ} \mathrm{C}$ axilar y disuria. Niega traumatismos, ingesta de fármacos y otros síntomas. Al examen físico genital: dos lesiones ulceradas, una en labio mayor derecho de $1 \mathrm{~cm}$, redondeada, bordes bien delimitados, indurada y fondo con exudado blanquecino. La otra, de $2 \mathrm{~cm}$ próxima a la horquilla vulvar con bordes más irregulares, exudado blanquecino en base y sector necrótico inferior, dolorosa (figura 2). Ingresa a cuidados moderados, se inicia amoxicilina sulbactam vía oral y se solicitan estudios complementarios expuestos en la tabla 1. En las primeras 24 horas de internación, retención aguda de orina; requiriendo anestésicos locales y analgésicos opioides reglados. A las 72 horas se objetivó una franca y rápida mejoría de las lesiones vulvares y se otorgó el alta. El planteo diagnóstico fue de úlceras vulvares agudas o de Lipschütz

\section{Caso 3}

Trece años, sin AP a destacar. Menarca a los 10 años, ciclos regulares. Niega IRS. 
Tabla 1. Características clínicas y paraclínicas de los casos.

\begin{tabular}{|c|c|c|c|c|c|c|c|}
\hline$N^{\circ}$ & $\begin{array}{l}\text { Edad } \\
\text { (años) }\end{array}$ & Antecedentes personales & IRS & $\begin{array}{c}\text { Síntomas } \\
\text { acompañantes }\end{array}$ & Estudios complementarios & $\begin{array}{c}\text { Planteo } \\
\text { diagnóstico }\end{array}$ & Tratamiento \\
\hline 1 & 14 & Úlceras orales recurrentes & No & $\begin{array}{l}\text { Fiebre, disuria, } \\
\text { dolor } \\
\text { abdominal }\end{array}$ & $\begin{array}{l}\text { VES } 27 \mathrm{~mm} / \mathrm{h} \\
\text { VEB y CMV no reactivos } \\
\text { ANA, ANCA no reactivos } \\
\text { C3, C4, CH50, FR normales. } \\
\text { Cámara anterior ojo con } \\
\text { lámpara de hendidura sin } \\
\text { alteraciones }\end{array}$ & $\begin{array}{l}\text { Enfermedad de } \\
\text { Behcet }\end{array}$ & $\begin{array}{l}\text { Analgesia } \\
\text { Sonda vesical } \\
\text { Antibióticos } \\
\text { Corticoides } \\
\text { Azatioprina }\end{array}$ \\
\hline 2 & 11 & No & No & $\begin{array}{l}\text { Fiebre, tos, } \\
\text { rinorrea, } \\
\text { disuria }\end{array}$ & $\begin{array}{l}\text { CMV IgG + } \\
\text { Serología VDRL, VIH, VHC } \\
\text { negativos } \\
\text { Ac. heterófilos VEB no reactivos } \\
\text { Exudado vaginal, anal y faríngeo } \\
\text { sin desarrollo bacteriano }\end{array}$ & $\begin{array}{l}\text { Úlceras de } \\
\text { Lipschütz }\end{array}$ & $\begin{array}{l}\text { Sonda vesical } \\
\text { Analgesia }\end{array}$ \\
\hline 3 & 13 & No & No & $\begin{array}{l}\text { Fiebre, dolor } \\
\text { abdominal, } \\
\text { disuria }\end{array}$ & $\begin{array}{l}\text { Serología HIV, VHB, VHC, } \\
\text { VDRL no reactivas. } \\
\text { Exudado vaginal sin desarrollo } \\
\text { bacteriano } \\
\text { VEB IgM + (EBNA y VCA) }\end{array}$ & $\begin{array}{l}\text { Úlcera de } \\
\text { Lipschütz asociada } \\
\text { a VEB }\end{array}$ & $\begin{array}{l}\text { Analgesia } \\
\text { Antibióticos } \\
\text { Antivirales } \\
\text { Corticoides }\end{array}$ \\
\hline 4 & 14 & No & No & $\begin{array}{l}\text { Fiebre, } \\
\text { odinofagia }\end{array}$ & $\begin{array}{l}\text { PCR } 19 \text { mg/l } \\
\text { VES } 69 \text { mm/h } \\
\text { Serología HIV, VDRL, virus } \\
\text { herpes simple } 1 \text { y 2, VHB y C no } \\
\text { reactivas } \\
\text { VEB IgG + IgM - } \\
\text { CMV IgG + IgM - } \\
\text { Anatomía patológica de lesión } \\
\text { resecada: tejido necrótico, vasos } \\
\text { dilatados, se observan } \\
\text { eritrocitos y leucopiocitos, } \\
\text { colonias bacterianas aisladas, } \\
\text { no elementos de malignidad. }\end{array}$ & $\begin{array}{l}\text { Úlceras de } \\
\text { Lipschütz }\end{array}$ & $\begin{array}{l}\text { Analgesia. } \\
\text { Sonda vesical. } \\
\text { Antibióticos. }\end{array}$ \\
\hline
\end{tabular}

IRS: inicio de relaciones sexuales; VES: velocidad de eritrosedimentación; VEB: virus Epstein-Barr; CMV: citomegalovirus; ANA: anticuerpos antinucleares; ANCA: anticuerpos anticitoplasma del neutrófilo; FR: factor reumatoideo; VDRL: Venereal Disease Research Laboratory; VIH: virus de inmunodeficiencia humana; VHC: virus hepatitis C; VHB: virus hepatitis B; EBNA: anticuerpos contra antígeno nuclear de Epstein-Barr; CVA: anticuerpos contra el antígeno de la cápside viral; PCR: proteína C reactiva.

Consulta por fiebre de 72 horas de evolución de $39^{\circ} \mathrm{C}$ axilar, dolor abdominal difuso y disuria. Refiere tumoración dolorosa a nivel genital. Niega traumatismos y administración de fármacos por vía sistémica o tópica. Examen físico: gran edema de labio mayor y menor derechos; en cara interna de labio mayor derecho lesión ulcerada indurada y dolorosa de $2 \mathrm{~cm}$, bordes irregulares y fondo con exudado blanquecino. En cara interna de labio mayor izquierdo, lesión en espejo de similares características, de 1 $\mathrm{cm}$; himen conservado (figura 3 ). Se inicia tratamiento con amoxicilina-clavulánico, metronidazol, azitromicina y aciclovir vía oral. Estudios complementarios expuestos en la tabla 1 . Se agrega tratamiento con corticoides y an- tibióticos tópicos. Dados en este caso los anticuerpos específicos para virus Epstein-Barr (VEB) IgM reactiva, el planteo diagnóstico fue de úlceras de Lipschütz asociadas a VEB. En control a las dos semanas se constata mejoría completa de las lesiones, sin recidivas ni aparición de úlceras en otras regiones.

\section{Caso 4}

Catorce años. Sobrepeso. Menarca a los 12 años, ciclos regulares. Niega IRS.

Consulta por fiebre y odinofagia de seis días de evolución. A las 48 horas del inicio de los síntomas agrega lesiones genitales dolorosas y asimetría del labio mayor 


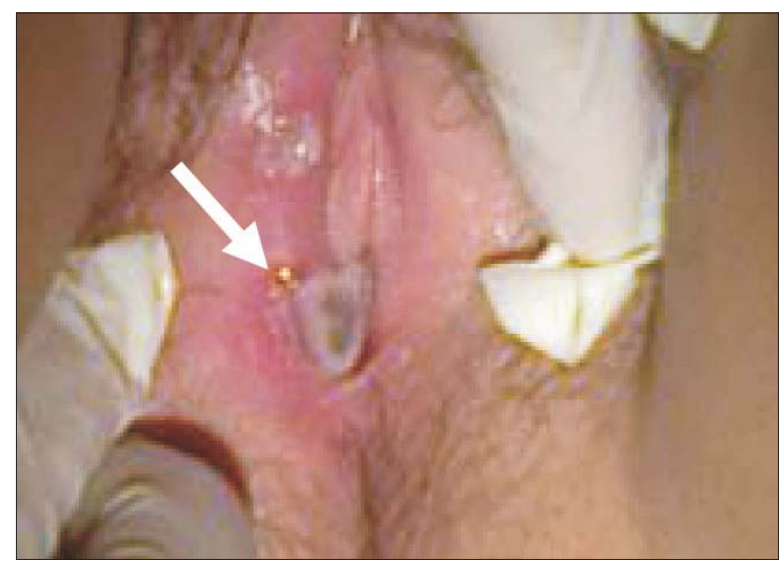

Figura 2. Se observan dos lesiones ulcerosas en labio mayor derecho, una en horquilla vulvar.

izquierdo. Niega ingesta de fármacos o traumatismos locales.

Valorada por ginecólogo, realiza decolamiento de cara interna de labio mayor por lesión ulcerada con área necrótica, que se envía a anatomía patológica (AP). Disuria intensa.

Examen físico: edema de labio mayor izquierdo, con lesión ulcerada en cara interna. Muy dolorosa y friable (figura 4). Ano sin lesiones. Resto normal. Ingresa a cuidados moderados por retención aguda de orina, se coloca sonda vesical, se inicia analgesia reglada por vía intravenosa con ketoprofeno, tramadol y tópica con lidocaína. Se comenzó tratamiento antibiótico con cefuroxime. Estudios complementarios expuestos en la tabla 1. Se planteó como diagnóstico úlceras vulvares de Lipschütz. Presentó buena evolución, alta al quinto día de internación con mejoría franca del dolor y de las lesiones.

Las principales características de los casos se resumen en la tabla 1.

\section{Discusión}

Los casos clínicos descriptos presentan algunas características en común que es necesario jerarquizar para el abordaje diagnóstico. Se trata de adolescentes que niegan IRS y conductas de riesgo y en las cuales no surge de la valoración clínica la sospecha de probable abuso sexual. Estas características orientan a la etiología no infecciosa.

La anamnesis detallada y exploración física minuciosa, analizando la forma de presentación (aguda, crónica, recurrente) y características de las úlceras son importantes para el diagnóstico diferencial ${ }^{(4)}$. En los antecedentes, además de considerar el IRS y la presencia de conductas de riesgo, se debe indagar acerca de ingesta

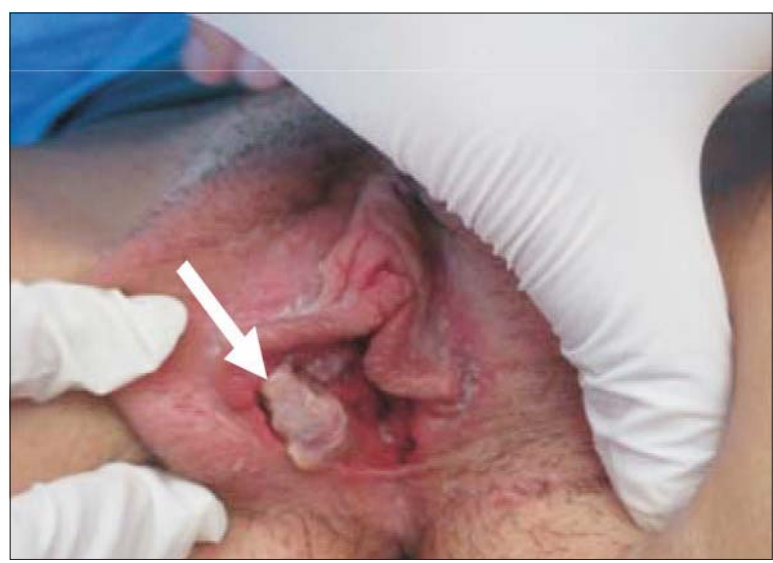

Figura 3. Se observa edema de labio mayor derecho y úlcera indurada.

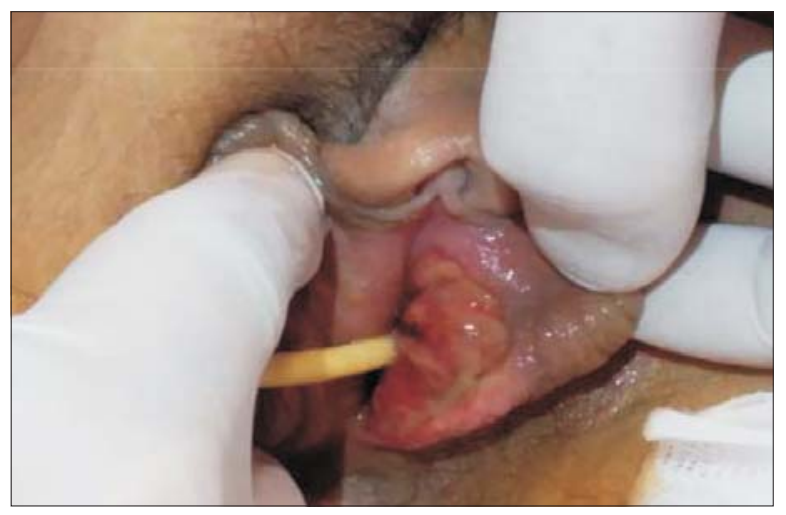

Figura 4. Gran lesión ulcerada en cara interna de labio mayor derecho con edema perilesional.

de fármacos, aplicación de fármacos o sustancias tópicas y traumatismos locales ${ }^{(2)}$.

En el caso 1, la forma de presentación recurrente con úlceras orales aleja las etiologías infecciosas. Entre las causas infecciosas la más frecuente es el VHS, cuya vía de transmisión no es exclusivamente sexual ${ }^{(4)}$. El VHS tipo 1 es más frecuente como causa de primoinfección genital y el VHS tipo 2 es más frecuente en general (70\%-90\%) y puede ser de presentación recurrente. Independientemente del subtipo de herpes, a diferencia de los casos descriptos, producen úlceras múltiples, pequeñas, agrupadas sobre una base eritematosa, superficiales, en ocasiones coalescentes, dolorosas y con prurito intenso. La segunda causa en frecuencia es la primoinfección por Treponema pallidum, que habitualmente pasa desapercibida por tratarse de lesiones únicas, indoloras y autolimitadas. El chancroide o chancro blando (Haemophilus ducreyi) comienza como pápulas eritematosas que evolucionan a pústulas y en 48 horas se ulceran. Son úlceras profundas y polimórficas, tienen 
Tabla 2. Criterios del International Study Group para el diagnóstico de enfermedad de Behcet.

\begin{tabular}{ll}
\hline Criterio & \multicolumn{1}{c}{ Descripción } \\
\hline Úlceras orales recurrentes & $\begin{array}{l}\text { Aftas pequeñas, aftas grandes o úlceras herpetiformes que recurren al menos tres veces en un período } \\
\text { de } 12 \text { meses, observadas por el médico o el paciente }\end{array}$ \\
Úlceras genitales recurrentes & Úlceras aftosas o cicatriz observada por el médico o el paciente \\
Lesiones oculares & $\begin{array}{l}\text { Uveítis anterior, uveítis posterior, células en el vítreo en la exploración con lámpara de hendidura o } \\
\text { vasculitis retiniana observada por oftalmólogo }\end{array}$ \\
Lesiones cutáneas & $\begin{array}{l}\text { Eritema nodoso observado por el médico o el paciente, pseudofoliculitis o lesiones pseudopustulosas o } \\
\text { nódulos acneiformes observados por el médico en paciente que ya ha pasado la adolescencia y que no } \\
\text { recibe tratamiento corticoideo } \\
\text { Reacción cutánea a la punción con una aguja observada por el médico a las 24-48 horas }\end{array}$ \\
\hline
\end{tabular}

Tomado de International Study Group for Behcet's Disease: Criteria for diagnosis of Behcet's disease, Lancet 335:1070-80, 1990.

base purulenta y borde violáceo-gris mal definido no indurado y fétidas. Suele encontrarse una úlcera dominante rodeada de otras satélites menores que pueden confluir en una mayor. Se localizan en horquilla vulvar, clítoris, vestíbulo y labios ${ }^{(2)}$.

Entre las causas no infecciosas se deben considerar enfermedades autoinmunes, como la enfermedad de Crohn, enfermedad de Behcet y pénfigo vulgar, y otras como liquen escleroso, aftosis idiopática, eritema fijo medicamentoso, eritema multiforme y enfermedades malignas o tumorales ${ }^{(3-6)}$. Como ya fue analizado, aunque en estos casos no surge la sospecha, se debe tener presente siempre la posibilidad de abuso sexual, ya que las lesiones vulvares pueden ser la única prueba ${ }^{(4,7,8)}$.

En el caso 1, como ya fue señalado, la forma de presentación orientó a enfermedad de Behcet. Se trata de una vasculitis caracterizada por úlceras orales y genitales recurrentes, uveítis y artritis. La paciente tenía el antecedente de úlceras orales recurrentes similares a úlceras aftosas, múltiples ${ }^{(2)}$. Para el diagnóstico de enfermedad de Behcet se aplican los criterios del International Study Group. Incluyen úlceras orales recurrentes; úlceras genitales recurrentes; lesiones oculares; lesiones cutáneas; patergia ${ }^{(9)}$. El signo de patergia es debido a hiperreactividad cutánea inespecífica; no es patognomónico. pero tiene una sensibilidad de $50 \%$ y especificidad de $98 \%$. Para buscar este signo se debe realizar un traumatismo mínimo en la piel (habitualmente con una aguja intradérmica) y se produce una pápula, esta reacción se lee a las 24-48 horas y se considera positiva si la pápula es mayor de $2 \mathrm{~mm}$. Los criterios diagnósticos de enfermedad de Behcet se muestran en la tabla $2^{(9,10)}$.

Si bien el caso 1 no cumplía con los dos criterios menores, se trata de formas de reciente comienzo en adoles- centes sin evidencia de enfermedad infecciosa, por lo que el seguimiento es esencial para aclarar el diagnóstico y descartar diagnósticos diferenciales ${ }^{(4)}$.

En los casos 2, 3 y 4 se trata de adolescentes, que al igual que la anterior, niegan antecedentes de IRS, pero en el contexto de un síndrome febril de reciente comienzo, presentan úlceras vulvares agudas dolorosas. Estas características coinciden con lo clásicamente descripto por Lipschütz a principios del siglo $\mathrm{XX}^{(2-11)}$. Esta entidad es conocida como úlceras de Lipschütz o ulcus vulvae acutum. Se trata de una entidad poco frecuente e infradiagnosticada, con un pico de incidencia entre los 10 y 15 años. La etiología y fisiopatología es desconoci$\mathrm{da}^{(4-12)}$. Se ha postulado la relación con la infección por diversos virus como influenza A, CMV, y principalmente por VEB. Estos virus podrían actuar como citotóxico directo sobre el epitelio vulvar o desencadenar una reacción inflamatoria sistémica ${ }^{(13,14)}$. En el caso 3 se observó asociación con infección por VEB. Se han asociado a infección por Mycoplasma pneumoniae ${ }^{(15)}$. Al igual que lo observado en esta serie, suelen presentarse con aparición súbita de úlceras únicas o múltiples en la vulva, periné o tercio inferior de la vagina, con típica disposición en espejo o kissing; con borde rojo y base necrótica cubierta con exudado gris $^{(5)}$. Se acompañan de fiebre, mialgias y adenopatías. Hay tres formas de presentación: gangrenosa, miliar y crónica. El diagnóstico es clínico y de exclusión. No es necesaria la biopsia, dado que arroja resultados inespecíficos. Se han propuesto una serie de criterios clínicos para el diagnóstico de las úlceras de Lipschütz; deben cumplirse cinco criterios mayores (úlcera genital aguda, edad menor de 20 años, ausencia de relaciones sexuales en los últimos tres meses, ausencia de inmunodeficiencia y resolución a las seis semanas 
del inicio de los síntomas) y uno menor: profundidad de la lesión (bien delimitada, dolorosa, centro necrótico o fibrinoso) y lesión bilateral (en espejo o beso). Los criterios de exclusión son antecedentes de aftosis genital, evidencia de infección por VHS u otra enfermedad de transmisión sexual e inmunodeficiencia ${ }^{(16)}$.

Es un proceso benigno de curso autolimitado, con resolución espontánea en dos a tres semanas, sin secuelas ni recidivas frecuentes, si bien en algunas comunicaciones se reportan recurrencias en hasta $33 \%$ en el primer año ${ }^{(3,16,17)}$. El tratamiento es sintomático; el objetivo es aliviar el dolor, mejorar la curación y prevenir la cicatrización $^{(4,16)}$.

No se ha demostrado que el uso de corticoides sistémicos modifiquen el curso de la enfermedad, estando indicada su utilización en mujeres con lesiones recurrentes o asociadas a aftosis oral ${ }^{(17)}$.

En todos los casos analizados se realizaron múltiples exámenes paraclínicos y antibioticoterapia sistémica.

En ocasiones, el dolor intenso de las úlceras vulvares genera complicaciones, como retención aguda de orina con necesidad de hospitalización para realizar analgesia y evacuación vesical por sonda, tal como ocurrió en los casos 1,2 y 4.

Resulta necesario el conocimiento de esta patología en niñas y adolescentes cuyo abordaje diagnóstico y terapéutico depende de la orientación etiológica basada en criterios epidemiológicos y clínicos bien definidos. Ello contribuirá a mejorar la calidad de la asistencia y contribuirá a minimizar las repercusiones biológicas y psicológicas.

\section{Conclusión}

Es importante que los pediatras estén familiarizados con las características epidemiológicas, clínicas y evolutivas de las diversas patologías que pueden causar úlceras vulvares en niñas y adolescentes, para realizar un diagnóstico y tratamiento adecuado y oportuno.

Se debe recordar que las úlceras vulvares pueden constituir un marcador de abuso sexual y enfermedades de transmisión sexual, y en adolescentes que no han iniciado relaciones sexuales, una manifestación de una patología benigna, como las úlceras de Lipschütz o el inicio de una enfermedad autoinmune, como la enfermedad de Behcet.

\section{Abstract}

Introduction: genital ulcers are characterized by great clinical and etiological heterogeneity. They may correspond to infectious or non-infectious skin or systemic pathologies. Lipschütz ulcer and Behcet disease stand out among non-infectious conditions.
Objective: to describe four clinical cases of adolescents with non-infectious severe vulvar ulcers hospitalized in two institutions of the national integrated health system in Montevideo, with the purpose of providing professionals with tools for the adequate diagnostic and therapeutic approach.

Discussion: a detailed anamnesis questionnaire and a thorough physical examination are of the essence for an adequate diagnostic and therapeutic approach. The clinical analysis should include considering the patient's age, initiation of sexual intercourse, the number, topography and characteristics of the ulcers including finding out whether there is pain or not, as well as the association of systemic manifestations.

It is important to learn about this rather unusual condition in girls and adolescents, whose diagnostic and therapeutic approach depends on the etiological orientation based on well-defined epidemiological and clinical criteria. This will contribute to improving the quality of assistance and minimizing biological and psychological effects.

\section{Resumo}

Introdução: as úlceras genitais se caracterizam por uma grande heterogeneidade clínica e etiológica. Podem ser causadas por patologias cutâneas ou sistémicas tanto infecciosas como não infecciosas. Entre as últimas, destacam-se as úlceras de Lipschütz e a doença de Behçet.

Objetivo: descrever quatro casos clínicos de adolescentes com úlceras vulvares agudas de causa não infecciosa hospitalizadas em duas unidades de saúde do sistema nacional integrado de saúde de Montevidéu buscando oferecer ferramentas para uma correta abordagem diagnóstica e terapêutica.

Discussão: é fundamental realizar uma anamnese detalhada e um exame físico minucioso para uma abordagem diagnóstica e terapêutica adequada. O exame clínico deve incluir a idade da paciente, o inicio das relações sexuais, o número, topografia e características das úlceras incluindo a presencia ou não de dor, bem como a associação com manifestações sistémicas.

É necessário conhecer esta patologia pouco frequente em meninas e adolescentes cuja abordagem diagnóstica e terapêutica depende da orientação etiológica baseada em critérios epidemiológicos e clínicos bem definidos. Isso contribuirá para melhorar a qualidade da assistência e a minimizar as repercussões biológicas e psicológicas.

\section{Bibliografía}

1. Díaz López L, Pavía Lafuente M, Vázquez Olaiz MC, Pascual Díez, M, Arluziaga Gondat M, Puente-Campano 
Fernández LE. Úlcera de Lipschütz con evolución tórpida a sinequia vulvar. Acta Pediatr Esp 2016; 74(8):e186-8.

2. Carputo R. Úlcera genital: diagnóstico diferencial y tratamiento. (Clases de residentes año 2012). Granada: Hospital Universitario Virgen de las Nieves, Servicio de Obstetricia y Ginecología, 2012:21 p.

3. Rubio P, Baquedano L, Gil E, Lapresta M. Úlcera genital aguda en paciente adolescente. Rev Chil Obstet Ginecol 2012; 77(6):450-2.

4. Hueto A, González G, Breton P, Zarate I, Lanuza R, Ferrer P. Úlceras genitales de Lipschütz: reporte de un caso pediátrico. Arch Argent Pediatr 2017; 115(6):e436-9.

5. Plácido R, Portillo M, del Castillo E, González M, Vaquerizo V. Úlcera de Lipschütz en su forma gangrenosa. Rev Pediatr Aten Primaria 2014; 16:e151-4.

6. Rivero Arias D, Ramos Gómez L, Chavez Caraza K, Briones A. Úlcera vulvar en una paciente de 15 años: ¿se puede reconocer la alergia a fármacos? Bol Med Hosp Infant Mex 2013; 70(3):230-3.

7. Burstein James F. Infecciones de transmisión sexual. En: Kliegman RM, Stanton MD, St. Geme J, Schor NF. Nelson. Tratado de Pediatría. 20ª ed. Madrid: Elsevier, 2016:1032-42.

8. Swerdlin A, Berkowitz C, Craft N. Cutaneous signs of child abuse. J Am Acad Dermatol 2007; 57(3):371-92. doi: 10.1016/j.jaad.2007.06.001.

9. Özen S. Enfermedad de Behcet. En: Kliegman RM, Stanton MD, St. Geme J, Schor NF. Nelson. Tratado de Pediatría. 20a ed. Madrid: Elsevier, 2016:1243-4.
10. Pimienta M, Olivé A. El fenómeno de la patergia. Semin Fund Esp Reumatol 2009; 10(3):87-90.

11. Mohedas A, Ballesteros M, Penela M, Rodríguez R, Prieto $\mathbf{S}$, Jiménez I. Úlceras de Lipschütz: a propósito de dos nuevos casos. Acta Pediatr Esp 2012; 70(4):169-70.

12. Lehman S, Bruce A, Wetter D, Ferguson S, Rogers R. Reactive nonsexually related acute genital ulcers: review of cases evaluated at Mayo Clinic. J Am Acad Dermatol 2009; 63(1):44-51. doi 10.1016/j.jaad.2009.08.038.

13. Mariño JC, Navarro M, Garrido M. Úlcera de Lipschütz por citomegalovirus. Clin Invest Gin Obst 2016; 43(1):32-4.

14. Maciel J, Kieselová K, Guiote V, Henrique M, Rezende T. Úlcera de Lipschütz como possível manifestação de primo-infeção por vírus Epstein-Barr. Nascer Crecer 2018; 27(1):50-3.

15. Koliou MG, Kakourou T, Richter J, Christodoulou C, Soteriades ES. Mycoplasma pneumoniae as a cause of vulvar ulcers in a non-sexually active girl: a case report. J Med Case Rep 2017; 11:187. doi: 10.1186/s13256-017-1345-9.

16. Eizaguirre FJ, Lucea L, Artola E, Goiri K. Úlcera genital aguda no relacionada con enfermedad de transmisión sexual. Anal Pediatr (Barc) 2011; 76(3):170-2. doi: 10.1016/j.anpedi.2011.09.015.

17. Kam S, Salomone C, Dossi MT, Tapia O. Úlcera genital aguda de Lipschütz: caso clínico. Rev Chil Obstet Ginecol 2014; 79(1):47-50.

\section{Contribución de autores}

Todos los autores participaron por igual en las distintas etapas de concepción, diseño, ejecución análisis, redacción y revisión crítica. Lucía Moreira, https://orcid.org/0000-0003-2319-9799.

Loreley García, https://orcid.org/0000-0002-4596-7448.

Ana Casuariaga, https://orcid.org/0000-0002-1122-5147.

Gustavo Giachetto, https://orcid.org/0000-0003-37754773.

Víctor Machín, https://orcid.org/0000-0001-7054-727X. 